\title{
LA PROBLEMÁTICA DERIVADA DEL RECONOCIMIENTO DE LOS EFECTOS DEL CONTRATO DE GESTACIÓN SUBROGADA DESDE LA PERSPECTIVA DEL DERECHO DEL TRABAJO Y DE LA SEGURIDAD SOCIAL
}

\section{THE PROBLEM DERIVED FROM RECOGNIZING THE EFFECTS OF GESTATION CONTRACT SUBROGATED FROM THE PERSPECTIVE OF LABOR LAW AND SOCIAL SECURITY}

\author{
David Tomás Mataix \\ Abogado \\ Doctorando en Derecho, Ciencia Política y Criminología (UV)
}

Recibido: 05.06.2019 / Aceptado: 05.07.2019

DOI: https://doi.org/10.20318/cdt.2019.4962

\begin{abstract}
Resumen: El contrato de gestación subrogada es nulo de pleno derecho en España por ser claramente contrario a los principios más esenciales de nuestro ordenamiento jurídico, siendo tal consecuencia expresada en la Ley 14/2006, de 26 de mayo. Pese a ello, de su celebración derivan una serie de efectos en el ámbito del Derecho del Trabajo y de la Seguridad Social, surgidos a partir de la creación de una nueva realidad familiar resultada del nacimiento de un menor de edad.

Palabras clave: maternidad subrogada, nulidad, derechos sociales, Seguridad Social, interés superior del menor.

Abstract: The surrogate motherhood contract is declared invalid in Spain because it is clearly contrary to the most essential principles of our legal system, this being expressed by the Law 14/2016, 26th of May. However, a series of effects derive from the celebration in the field of Labor and Social Security Law, arising from the creation of a new family reality resulting from the birth of a minor.

Keywords: surrogate motherhood, nullity, social security, social rights, children's interest.

Sumario: I. Introducción. II. La gestación subrogada a la luz de la jurisprudencia del Tribunal Europeo de Derechos Humanos. III. Sucinta mención al marco jurídico de la gestación subrogada en el derecho español. IV. Maternidad subrogada y la prestación por nacimiento y cuidado de menor. Una cuestión de interpretación. 1. Una visión anterior a la reforma mediante el RD-Ley $6 / 2019$, de 1 de marzo. 2. La gestación subrogada frente a la prestación por nacimiento y cuidado de menor. Nuevas perspectivas interpretativas de la norma. V. Conclusiones.
\end{abstract}

\section{Introducción}

1. La gestación por sustitución entraña un arduo debate donde entran en juego argumentos éticos, políticos e incluso religiosos. Empero, de todos es sabido que en España, en los últimos treinta años, el modelo de familia ha dado un giro radical llegando a normalizar diferentes tipos de concepciones al término familia. Uno de estos nuevos modelos de familia que ha emergido en estas últimas décadas ha sido el nacido a través de un contrato de gestación subrogada. 
2. Tal y como ha venido definiendo la doctrina ${ }^{1}$, la gestación por sustitución es un supuesto especial de reproducción humana asistida mediante el cual una mujer, mediando acuerdo previo, ya fuere con precio o sin él, se obliga a gestar un bebé con el mero fin de entregarlo después del alumbramiento para que otra $u$ otras personas puedan ser padres biológicos o no, renunciando, consiguientemente, a su filiación. Este técnica es conocida también, entre otras acepciones, como maternidad portadora, suplente, sustitutiva o de encargo, localización de vientres o contrato de servicios de incubación de un útero ajeno. De tal modo que, en realidad, la gestación subrogada es una técnica por medio de la cual una mujer porta en su vientre un embrión implantado hasta el nacimiento, para el beneficio de otra mujer, de un hombre, o de una pareja, ya fuere matrimonial, no matrimonial, heterosexual u homosexual.

3. Dejando al margen el concepto, y como analizaremos durante esta disertación legal, el contrato de gestación subrogada es nulo de pleno derecho en aplicación del artículo 10 de la Ley de Técnicas de Reproducción Humana Asistida, así como por ser contrario al ordenamiento jurídico español. Sin embargo, y pese a la nulidad señalada, no es menos cierto que de su celebración se han derivado una serie de efectos, en concreto, como he señalado anteriormente, la creación de una nueva realidad familiar emanada del nacimiento de menores de edad.

4. Se debe agregar que, sin olvidar la ineludible nulidad radical del convenio de gestación subrogada, hoy día el legislador no ha dado solución alguna a la regulación de los efectos surgidos del mismo, es decir, al nacimiento de los menores. De tal suerte que, la respuesta a dichos conflictos ha venido dada, en primer lugar, en el ámbito del Derecho Civil, por una interpretación de la norma por parte de la Dirección General de los Registros y del Notariado; y, en segundo lugar, desde el ámbito del Derecho del Trabajo y de la Seguridad Social, a través de una interpretación analógica de la normativa social realizada por parte de la Sala Cuarta del Tribunal Supremo que, a su vez, ha sido asumida por parte del Instituto Nacional de la Seguridad Social. Consecuentemente, en la actualidad, todos aquellos recién nacidos mediante un convenio de gestación subrogada se encuentran en un limbo jurídico donde la única solución radica en la interpretación analógica realizada por los tribunales de justicia.

5. En lo que se refiere a las prestaciones de la Seguridad Social, resulta elemental señalar que estas guardan una íntima relación con el derecho a la igualdad, proclamado en el artículo 14 de la Constitución Española. En particular, con el derecho a la igualdad independientemente de las circunstancias que rodearon el nacimiento de las personas. De otro lado, no es baladí hacer mención que el constituyente estableció en el artículo 39 de la Constitución Española la imperiosa obligación de los poderes públicos de asegurar la protección social, económica y jurídica de la familia, así como la protección de los hijos, independientemente de su filiación. Por consiguiente, y en principio, el legislador vendría obligado a establecer los mecanismos legales oportunos a fin de proteger el cuidado del menor, a través de las prestaciones o derechos sociales correspondientes, y todo ello sin hacer distinción alguna sobre el modo por medio del cuál éste ha sido engendrado.

\section{La gestación subrogada a la luz de la jurisprudencia del Tribunal Europeo de Derechos Humanos}

6. Con carácter previo al sucinto estudio de los diferentes pronunciamientos del Tribunal Europeo de Derechos Humanos (TEDH)², en relación a los efectos del convenio de gestación subrogada en cuanto a la inscripción de los menores se refiere, debemos dejar patente que el TEDH no entra a valorar sobre la legalidad de los convenios de gestación subrogada, pues, además, reconoce la disparidad de regulaciones existentes en los diferentes países que componen la Unión Europea. Por tanto, el TEDH ha venido pronunciándose sobre casos concretos, analizando si la medida adoptada por un país concreto ha supuesto o no una vulneración de derechos regulados en el Convenio Europeo de Derechos Humanos.

\footnotetext{
${ }^{1}$ Entre otros, A. J. Vela SÁnchez, La maternidad subrogada: estudio ante un reto normativo. Editorial Comares, 2012, p. 1.

${ }^{2}$ Estas sentencias son analizadas en profundidad en L. Pertusa Rodríguez, "Dimensión consular de la gestación por sustitución en Derecho Internacional Privado". Cuadernos de Derecho Transnacional, vol. 10, núm. 2, pp. 604-605.
} 
7. Dicho esto, el TEDH, en las sentencias de los casos Mennesson c. Francia y Labasse c. Francia, de 26 de junio de 2014 donde resolvió la demanda interpuesta por los padres intencionales tras ver negada por los Tribunales franceses la inscripción de la filiación de los menores en Francia, falló a favor de los padres intencionales. Así, a fin de justificar tal decisión, el Tribunal, atendiendo la nueva realidad familiar surgida del nacimiento de los menores, y considerando que el derecho da la identidad forma parte del concepto de intimidad, entendiendo que el rechazo al reconocimiento de la filiación de los menores a favor de los padres comitentes vulneraba el derecho a la vida privada de los menores regulado en el artículo 8 del Convenio Europeo de Derechos Humanos (en adelante, CEDH). Es decir, el TEDH consideró que la actitud de Francia -donde la gestación subrogada está prohibida- vulneraba el interés de los menores, así como su derecho a la vida privada ${ }^{3}$.

8. De la misma forma resolvió el TEDH en el caso Paradiso y Campanelli c. Italia. En este caso, al contrario de los anteriores, no existía relación biológica entre los menores y los padres comitentes. Pese a ello, el Tribunal reconoció que existía una vida familiar de facto aunque ésta sólo hubiera durado 6 meses, y ello a pesar de la inexistencia de tal vínculo. Consiguientemente, declaró la negativa de Italia de inscribir a los menores como hijos de los padres comitentes en Italia como una decisión que vulneraba flagrantemente el derecho a la vida privada de los menores del artículo $8 \mathrm{CEDH}$. Empero, la resolución que ponía fin al caso Paradiso y Campanelli c. Italia fue revisada y, finalmente, revocada, mediante la sentencia de 24 de enero de 2017, dictada por la Gran Sala del Tribunal Europeo de Derechos Humanos.

9. Como decimos, la Gran Sala consideró -al contrario que en las anteriores resoluciones mencionadas- que el dato relativo al vínculo biológico era del todo relevante. De modo que, estimó que debido a la no existencia de vínculo entre el menor y los padres comitentes, sumado a la corta duración en la relación y su consecuente falta de afianzamiento familiar desde una perspectiva jurídica, la decisión de los tribunales italianos no atentaba contra ningún derecho reconocido en la CEDH. Así, el TEDH consideró que los Tribunales italianos habían actuado correctamente, dando una solución equilibrada a un supuesto donde los padres comitentes habían cometido una acto ilegal, movidos por un sentimiento narcisista.

10. Sin embargo, recientemente, el día 4 de abril de 2019, el Tribunal Europeo de Derechos Humanos emitió opinión consultiva en respuesta a la solicitud presentada por el Tribunal de Casación de Francia, acordando por unanimidad en un supuesto de gestación subrogada donde existe vínculos biológicos entre el padre y el niño recién nacido, habiéndose utilizado gametos de una tercera donante, que:

- "El derecho del niño al respeto de su vida privada en el sentido del artículo 8 del Convenio exige que la legislación nacional prevea la posibilidad de reconocer una relación jurídica paterno-filial con la madre comitente, designada en el certificado de nacimiento legalmente establecido en el extranjero como "madre legítima";

- El derecho del niño al respeto de su vida privada en el sentido del artículo 8 del Convenio no exige que dicho reconocimiento adopte la forma de inscripción en el registro de nacimientos, matrimonios y defunciones de los datos de la partida de nacimiento legalmente establecida en el extranjero; pueden utilizarse otros medios, como la adopción del niño por la madre comitente, siempre que el procedimiento establecido por la legislación nacional garantice que pueda ser aplicado con prontitud y eficacia, de conformidad con el interés superior del niño"4; garantizando -al margen de la apreciación que disponen los Estados en

${ }^{3}$ O. Salazar Benítez, La gestación para otros: Una reflexión jurídico-constitucional sobre el conflicto entre deseos y derechos. Editorial Dykinson, S.L, Madrid, 2018, p. 131.

${ }^{4}$ Podemos encontrar la opinión consultiva traducida al español en la web del Ministerio de Justicia. En concreto, en el siguiente enlace: https://www.mjusticia.gob.es/cs/Satellite/Portal/1292429190384?blobheader=application\%2Fpdf\&blobheadername

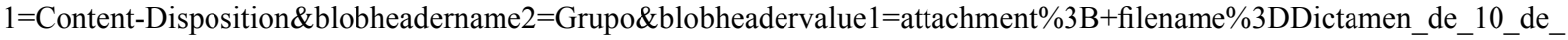
abril_de_2019_en_relacion_con_el_reconocimiento_en_el_Derecho_interno_de_una_rela.PDF\&blobheadervalue2=Docs_ TEDH_Tribunal 
cuanto a la elección de los medios- que exista un procedimiento sucinto y eficaz que garantice el interés superior del menor".

11. Por tanto, como se aprecia con anterioridad de las conclusiones que se relacionan, el TEDH parece haber cambiado radicalmente de postura, considerando que el Estado debe tomar las medidas necesarias, rápidas en su trámite, oportunas y eficaces a fin de salvaguardar el interés superior del menor.

\section{Sucinta mención al marco jurídico de la gestación subrogada en el derecho español}

12. Del mismo modo que en la mayoría de países de la Unión Europea ${ }^{5}$, el legislador español ha establecido la total y absoluta nulidad del convenio de gestación subrogada a través de la Ley 14/2006, de 26 de mayo, sobre Técnicas de Reproducción Humana Asistida. En efecto, en el apartado primero del artículo 10 de la mencionada ley se establece que será nulo de pleno derecho el contrato por el que se convenga la gestación, con o sin precio, a cargo de una mujer que renuncia a la filiación materna a favor del contratante o de un tercero; es más, los apartados segundo y tercero del artículo reseñado vienen a determinar que la filiación de aquellos hijos nacidos mediante esta técnica vendrá dada por el parto, independientemente de la relación biológica de la madre gestante con el recién nacido, estableciéndose la posibilidad de que el progenitor biológico pueda reclamar la maternidad o paternidad a través de las reglas generales establecidas en el Código Civil.

13. Empero, y al margen de la prohibición legal mencionada, la figura de la gestación subrogada es -según sectores doctrinales-radicalmente nula al ser claramente contraria a los principios más esenciales de nuestro ordenamiento jurídico. En efecto, a la misma conclusión llegaríamos en aplicación del artículo 1.271 del Código Civil, el cual prescribe que tan solo pueden ser objeto de contrato aquellas cosas que no están fuera del comercio de los hombres ${ }^{6}$, de tal manera que cualquier contrato cuyo objeto fuera cualquier elemento del cuerpo humano sería nulo de pleno derecho, dado que se considera que el cuerpo humano es un bien inalienable que queda al margen de cualquier facultad de disposición ${ }^{7}$. De igual modo lo apunta el propio artículo 1.275 del Código Civil, el cual establece con claridad meridiana que de todo contrato cuyo causa sea ilícita no emergerá efecto alguno ${ }^{8}$. Es más, algún sector doctrinal ${ }^{9}$ ha venido considerando que el contrato de gestación subrogada es ilegal por inconstitucional dado que la celebración de éste iría en contra de la dignidad reconocida en el artículo 10.1 de la Constitución Española. Por todo ello, y siguiendo las afirmaciones de este sector doctrinal, es ilegal, por inconstitucional, todo contrato que tenga como objeto la prestación de un embarazo por sustitución, y ello por vulnerar el necesario respeto a la dignidad de la persona, en concreto, la dignidad de la madre gestante, así como la del niño gestado. De modo similar, la Sala Primera del Tribunal Supremo, a través de la sentencia de 6 de febrero de $2014^{10}$, señaló que el contrato de gestación subrogada es incompatible con las normas que regulan

${ }^{5}$ Dirección general de políticas InTERIORes, "El régimen de subrogación en los países miembros de la UE". Derechos de los ciudadanos y asuntos constitucionales, 2013. Disponible en http:/www.europarl.europa.eu/RegData/etudes/ STUD/2013/474403/IPOLJURI_ET(2013)474403(SUM01)_ES.pdf [fecha de consulta 13 de marzo de 2018].

${ }^{6}$ A. Hernández Rodríguez, "Determinación de la filiación de los nacidos en el extranjero mediante gestación por sustitución: ¿hacia una nueva regulación legal en España?”. Cuadernos de Derecho Transnacional, vol. 6, núm. 2, p. 151.

7 "Las cosas de tráfico prohibido. Aqui se incluyen ciertos bienes de tráfico restringido, como armas, explosivos, etcétera. También el cuerpo humano, se ha considerado tradicionalmente res extra comercium, incluso tras el fallecimiento (el cadáver). Así la legislación sobre trasplantes de órganos prohibe expresamente la venta de órganos, tanto en vida, como tras el fallecimiento del sujeto". F. MARIÑo PARDo, Las cosas: concepto y clasificación. Bienes muebles e inmuebles. Bienes de dominio público y de propiedad privada. El patrimonio y sus tipos". Septiembre, 2015. Disponible en http://www.franciscomarinopardo.es/mis-temas/41-temas-10-27-parte-general-programa-2015/156-tema-20-las-cosas-concepto-y-clasificacion [fecha de consulta: 27 de marzo de 2019].

${ }^{8}$ A. Selma Penalva, "Vientres de alquiler y prestación por maternidad". Revista Doctrinal Aranzadi Social núm. 9/2013. Editorial Aranzadi, S.A.U., Cizur Menor, 2013, p. 3.

${ }^{9}$ Por todos, M. L. Balaguer Castejón, Hij@s del mercado. La maternidad subrogada en un Estado Social. Ediciones Cátedra (Grupo Anaya, S.A.), 2017, p. 83.

10 "De manera sintética, conviene recordar que la STS 6 febrero 2014 sostuvo lo siguiente: (i) Que la cuestión no podía resol- 
aspectos esenciales de las relaciones familiares, en concreto de la filiación, inspiradas en los valores constitucionales de dignidad de la persona, respecto de la integridad moral y protección a la infancia.

14. Sin embargo, y pese a tal pronunciamiento emitido por el Alto Tribunal, el debate relativo a la posible vulneración de la dignidad de la persona en los supuestos de gestación subrogada es dispar, y no sólo a nivel nacional. Recientemente, el Tribunal Constitucional portugués declaró la inconstitucionalidad de algunos puntos con contradecían derechos protegidos constitucionalmente ${ }^{11}$ de la Ley $\mathrm{n}^{\mathrm{o}}$ 25/2016 de 22 de agosto, reguladora del acceso a la gestación por sustitución. Sin embargo, y pese a ello, el Tribunal Constitucional portugués entendió que la norma reguladora del acceso a la gestación subrogada no vulneraba el derecho a la dignidad de la mujer, argumentando que la inconstitucionalidad de la norma devenía por vulnerar otros principios y derechos fundamentales consagrados en la Constitución portuguesa. Por tanto, como vengo a poner de relieve, el debate acerca de la vulneración o no de la dignidad de la mujer en la suscripción de un convenio de gestación subrogada traspasa las fronteras nacionales, siendo esta cuestión planteada por parte de otros órganos judiciales europeos.

15. Al margen de lo anterior y avanzando en el análisis del controvertido contrato, debemos hacer un pequeño inciso en relación a los efectos del contrato de gestación subrogada, en concreto, a la inscripción de los menores de edad. El Tribunal Supremo en su sentencia de fecha 6 de febrero de 2014 (rec. 245/2012) denegó la inscripción de dos hijos nacidos por gestación subrogada, considerando que debía prevalecer el orden público internacional español frente al interés superior del menor, derivando a los progenitores al procedimiento de reclamación de paternidad -en el supuesto de que alguno de los padres fuera biológico-, ex artículo 10.3 LTRHA o a los trámites de adopción o acogimiento familiar. Tras este pronunciamiento del Tribunal Supremo, las inscripciones en el Registro Civil fueron paralizadas. No obstante, y tras considerar la DGRN que la nueva jurisprudencia del TEDH ${ }^{12}$ superaba lo hasta ahora acordado por el Alto Tribunal, decidió emitir la Circular de fecha 11 de julio de 2014, dotando de plena eficacia a la Instrucción de 5 de octubre de 2010. Esta instrucción, grosso modo, ha venido exigiendo para la inscripción de un menor nacido mediante esta técnica, que exista una resolución judicial dictada por el órgano judicial competente en la que determine la filiación del nacido, requiriendo -salvo que existiere Convenio internacional- que dicha resolución supere el trámite de exequatur. Además, y en el caso de que la filiación hubiera sido acordada en un procedimiento análogo a uno español de jurisdicción voluntaria, se establece la obligación de que el encargado del Registro Civil haga un control incidental de los circunstancias en las que se ha desarrollado el contrato de gestación subrogada.

16. Pese a tales directrices, y con el fin de solventar las vicisitudes ocurridas por el no reconocimiento de filiaciones derivadas de contratos de gestación subrogada celebrados en Ucrania, la DGRN emitió la Instrucción de 14 de febrero de 2019 ampliando los requisitos para la inscripción de los menores nacidos mediante gestación subrogada a aquellos supuestos en los que se pudiera certificar a través de una prueba de ADN. Sin embargo, escasos días después, la DGRN volvió a emitir una nueva Instrucción de fecha 18 de febrero, dejando sin efecto la anterior y acordando mantener los requisitos exigidos en la Instrucción de 5 de octubre de 2010.

verse mediante la aplicación pura y simple del Derecho español, esto es, del citado art. 10 de la Ley 14/2006; (ii) Que tampoco era aplicable el art. 9.4 CC, según el cual la filiación se rige por la Ley nacional del hijo; (iii) Que no hacía falta ninguna sentencia o resolución judicial extranjera que acreditase la filiación de los nacidos en virtud de gestación por sustitución; (iv) Que el único requisito que se exigía para aceptar la inscripción en el Registro Civil español de la filiación de estos menores contenida en el acta registral extranjera, consistía en acreditar que la certificación registral extranjera no vulneraba el orden público internacional español. El TS entendió que sí lo vulneraba y denegó los efectos jurídicos en España de dicha certificación registral extranjera. Esto es, visto que, a juicio del TS, la resolución o acta registral extranjera en la que constaba la filiación de estos menores en favor de sus comitentes con arreglo al Derecho extranjero vulneraba el orden público internacional español, dicha resolución registral no podía operar como título apto para inscribir tal filiación en el Registro Civil español”. Extracto extraído de A. L. CALvo CAravaca y J. Carrascosa González, "Gestación por sustitución y Derecho Internacional Privado. Más allá del Tribunal Supremo y del Tribunal Europeo de Derecho Humanos." Cuadernos de Derecho Transnacional, vol. 7, núm. 2, p. 70.

${ }^{11}$ Disponible en http://www.tribunalconstitucional.pt/tc/acordaos/20180225.html [fecha de consulta: 18 de marzo de 2018].

${ }^{12}$ Téngase en cuenta que en 2014 aún no se había pronunciado la Gran Sala del TEDH a través de la sentencia de fecha 24 de enero de 2017. 


\section{Maternidad subrogada y la prestación por nacimiento y cuidado de menor. Una cuestión de interpretación}

\section{Una visión anterior a la reforma mediante el RD-Ley 6/2019, de 1 de marzo}

17. Como de un somera lectura se podía extraer de los preceptos reguladores de la prestación por maternidad y paternidad, la gestación subrogada no se encontraba entre las situaciones expresamente protegidas por la citada prestación. De tal forma que, tanto el artículo 48 del Estatuto de los Trabajadores, como el artículo 177 de la Ley General de la Seguridad Social, consideraban que tan sólo serán situaciones protegidas la maternidad, la adopción, la guarda con fines de adopción y el acogimiento familiar, de conformidad con el Código Civil o las leyes civiles autonómicas, siempre que, en este último caso, su duración no fuere inferior a un año. Por tanto, la gestación subrogada, en principio, y en aplicación literal de la citada normativa, no se encontraba entre las situaciones protegidas por la prestación por maternidad.

18. No obstante, el Real Decreto 295/2009, de 6 de marzo, por el que se regulaban las antiguas prestaciones de maternidad y paternidad, en particular en el artículo 2, apartado segundo, establece que también podrán ser beneficiarios de la prestación de maternidad aquellas instituciones jurídicas declaradas por resoluciones judiciales o supuestos de adopción y acogimiento preadoptivo, simple o permanente, cuya duración no fuera inferior a un año, cualquiera que fuere su denominación. De tal forma que podríamos llegar a entender a través de una interpretación analógica ${ }^{13}$ de la normativa de desarrollo que el legislador quiso establecer un listado parcialmente abierto y, por consiguiente, la maternidad subrogada tendría total encaje en el precepto. De la misma forma lo entendió la Sala Cuarta del Tribunal Supremo $^{14}$, pues así ha venido afirmando que la lista establecida en el artículo 2.2 del RD 295/2009, de 6 de marzo tiene un carácter parcialmente abierto, permitiendo una cierta flexibilidad normativa.

19. Como apuntó el Tribunal Supremo antes de la reforma de la prestación de maternidad y paternidad mediante el Real Decreto-Ley 6/2019, de 1 de marzo, el listado de contingencias protegidas por nuestro ordenamiento jurídico, recogido en el mencionado artículo 2, apartado segundo, del RD 295/2009, es un listado parcialmente abierto, pues de él se desprende una relativa apertura del elenco de supuestos protegidos por nuestro ordenamiento, lo que permite una cierta flexibilidad normativa ${ }^{15}$. Acorde con lo anterior, y resultado de esta regulación laxa o flexible de la norma, podríamos entender que, mediante una interpretación analógica, que la maternidad subrogada está dentro de los supuestos protegidos en el RD 295/2009, de 6 de marzo. Esta postura fue acogida por numerosas salas de lo social de distintos Tribunales de Justicia, entre ellas la Sala de los Social del Tribunal Superior de Justicia de Castilla- La Mancha, de 27 de mayo de 2015, quien consideró que el hecho que el ordenamiento jurídico no reconozca expresamente a los efectos del derecho a la prestación de maternidad, otras figuras análogas a la maternidad biológica, no puede interpretarse que éstas están excluidas de protección.

20. A su vez, el Tribunal Supremo señaló que se debía realizar una interpretación de la norma favorable a la concesión de la prestación de maternidad en los supuestos de gestación por sustitución en base al interés superior del menor, así como en protección del principio de igualdad, ambos eje central y prioritario de nuestro ordenamiento jurídico y constitucional. Así, en primer lugar, y en lo que se refiere al interés del menor, se argumentó por parte del Tribunal que la denegación del permiso de maternidad pudiera lesionar el citado principio en tanto en cuanto se priva al progenitor de dispensar aquellos cuidados esenciales en los primeros meses de vida debido a una falta de protección del sistema español de

\footnotetext{
${ }^{13}$ Según establece el artículo 4.1 del Código Civil, "procederá la aplicación analógica de las normas cuando éstas no contemple un supuesto especifico, pero regulen otro semejante entre los que se aprecie identidad de razón".

${ }^{14}$ Entre otras, STS, de 25 de octubre de 2016, n 5375/2016, ECLI:ES:TS:2016:5375.

${ }^{15}$ C. Aragón Gómez, "La legalización de facto de la maternidad subrogada. A propósito de los recientes pronunciamientos de la sala de lo social del Tribunal Supremo con respecto a las prestaciones de maternidad". Revista de Información Laboral núm. 4/2017 parte Art. Doctrinal. Editorial Aranzadi, S.A.U., Cizur Menor, 2017, p. 9.
} 
Seguridad Social. En segundo lugar, y en relación a la protección del principio de igualdad, el Tribunal argumentó que el artículo 39.2 de la Constitución Española indica la imperiosa necesidad de que los poderes públicos aseguren una protección integral de los hijos nacidos, independientemente de la filiación de los mismos. Por ende, negar la prestación de maternidad en los supuestos de gestación subrogada supondría una clara vulneración del principio de igualdad al tratar de forma desigual a aquellos hijos nacidos mediante un convenio de gestación subrogada, y ello conllevaría una privación de la asistencia al menor y, por consiguiente, una vulneración del precepto constitucional, así como una multitud de tratados internacionales suscritos por el Estado españo ${ }^{16}$.

21. Por otra parte, el Tribunal Supremo argumentó que dotar de protección a aquellos niños nacidos mediante gestación por sustitución a través de la prestación de maternidad no suponía una contradicción a las normas de la Unión Europea. Así fue reconocido por la propia Gran Sala del Tribunal de Justicia de la Unión Europea ${ }^{17}$ a través de una interpretación literal del artículo 8 de la Directiva 92/85/ CEE del Consejo, de 19 de octubre de 1992, relativa a la aplicación de las medidas para promover la mejora de la seguridad y de la salud en el trabajo de la mujer trabajadora, la cual excluye del ámbito de aplicación de cualquier situación de maternidad ajena a la biológica, incluso cuando se proporciona de manera efectiva los cuidados que el menor de edad requiere, reconociendo que los Estados miembros tienen potestad para establecer en sus legislaciones regulaciones más favorables, incorporando el derecho a la prestación por maternidad a otros supuestos no contemplados en la Directiva, es decir, a supuestos que van más a allá de la maternidad biológica.

22. A su vez, y en relación a la justificación de la aplicación analógica de la norma, la Sala de lo Social del Tribunal Supremo entendió que, en los supuestos de gestación subrogada donde no existe una relación biológica entre los padres comitentes y el recién nacido, la posición de los padres comitentes podría ser similar a un proceso de adopción o acogimiento y, por consiguiente, dicha similitud justificaría la aplicación analógica de la norma ${ }^{18}$. Es más, indicó que éste tan sólo sería un argumento adicional en los supuestos de filiación biológica por parte de uno -o de ambos- de los progenitores comitentes, pues en ese supuesto, el progenitor biológico podría tener acceso a la prestación de maternidad aplicando analógicamente los apartados tercero y cuarto del artículo 3 del Real Decreto 295/2009, de 6 de marzo. Ambos apartados hacen referencia a supuestos donde la madre gestante no tiene opción de disfrutar de la prestación por maternidad bien porque ha fallecido o porque es una trabajadora por cuenta propia y no tiene derecho a la citada prestación. Y ello por considerar que ambas situaciones son semejantes al supuesto de gestación subrogada donde uno -o ambos- de los comitentes es progenitor biológico del neonato y la madre gestante renuncia a la patria potestad del recién nacido produciéndose su ausencia dentro del núcleo familiar, y ello conduciría sólo el progenitor biológico pudiera afrontar los cuidados propios y, por ende, tan sólo este estuviera en condiciones de disfrutar de la prestación por maternidad. Igualmente, y de una forma más clarificadora, el Tribunal Supremo, en su sentencia 4816/2017, de 30 de noviembre, entendió que, al margen de la argumentación señalada anteriormente, se debía otorgar la prestación de maternidad al entenderse que, en los supuestos donde concurre la paternidad biológica de quien demanda las prestaciones, ese recurso interpretativo es sólo adicional, pues la maternidad por subrogación, como su propio nombre indica, puede abordarse como una especie o subtipo reconducible a la categoría general.

23. Enlazando con lo anterior, la jurisprudencia del Tribunal Supremo ${ }^{19}$ ha venido reiterando que se ha generado un estado de necesidad merecedor de protección a través de la prestación de maternidad, al margen de la nulidad y la consecuente ineficacia que implica el contrato de gestación subrogada. Admitiendo que, pese a que la Ley 14/2006 regula expresamente la nulidad del convenio de gestación

\footnotetext{
${ }^{16} \mathrm{M}^{\mathrm{a}}$. D. ORTIZ VIDAL, "La gestación por sustitución y las prestaciones sociales por maternidad/paternidad en España y la novísima jurisprudencia del Tribunal de Justicia de la Unión Europea". Revista Española de Derecho del Trabajo, 2015, p. 14.

${ }^{17}$ STJUE de 18 de marzo de 2014, C.D contra S.T, C-167/12, ECLI:EU:C:2014:169.

${ }^{18}$ Entre otras, STSJ Catalunya de 23 de noviembre de 2012, n ${ }^{\circ}$ 12193/2012, ECLI:ES:TSJCAT:2012:12193.

19 Por todas, STS de 22 de marzo de 2018, n 1242/2018, ECLI:ES:TS:2018:1242.
} 
subrogada, ésta no resulta de aplicación a los supuestos de prestaciones de la Seguridad Social, dado que la norma no regula la prestación de maternidad, ni tiene por objeto la protección de los menores a través de la atención directa de sus progenitores. Acorde con lo anterior, se afirma que el ordenamiento laboral no es ajeno al reconocimiento de efectos en negocios jurídicos nulos, siendo reconocido, por ejemplo, el derecho al salario por el tiempo en el que un trabajador trabajó al amparo de un contrato nulo. De hecho, como indicó el Tribunal Superior de Justicia del País Vasco en una reciente sentencia ${ }^{20}$, es indiferente la legalidad o ilegalidad del contrato o negocio suscrito entre el beneficiario y la madre del menor. Lo importante es que nuestro ordenamiento protege las situaciones de la relación creada, y de excluir un supuesto como el de la maternidad subrogada es discriminar esa misma relación frente a otros supuestos como los que acoge el artículo 177 LGSS, de adopción, o de guarda con fines de adopción y acogimiento familiar. Eso es lo relevante, y en tal sentido es en el que se ha pronunciado nuestro Tribunal Supremo ${ }^{21}$.

24. En síntesis, en opinión de la Sala Cuarta del Tribunal Supremo, que el ordenamiento jurídico prescriba la nulidad radical del contrato de gestación subrogada, no elimina la situación surgida del mismo por el nacimiento del menor y su inserción en el núcleo familiar, situación que debe ser afrontada desde la perspectiva de las prestaciones de la Seguridad Social protegiendo los derechos de los menores de edad ${ }^{22}$.

25. Llegados a este punto, debemos hacer mención a la interpretación realizada por parte del Instituto Nacional de la Seguridad Social al respecto.

26. Por medio de las consultas 29/2016, de 29 de diciembre, y 4/2017, de 20 de febrero, de la Subdirección General de Ordenación y Asistencia Jurídica del Instituto Nacional de la Seguridad Social, la Entidad gestora asumió y acató la doctrina sentada en las sentencias dictadas por el Pleno de la Sala de lo Social del Tribunal Supremo ${ }^{23}$ reconocimiento el derecho a la prestación por maternidad que antes de la reforma estuvo prevista en el artículo 177 de la Ley General de la Seguridad Social a los progenitores de hijos nacidos mediante un contrato de gestación subrogada acorde con la legalidad vigente en el país extranjero. Aunque, tal y como afirma la doctrina científica, estos criterios interpretativos del INSS tan solo recogen de una forma uniforme los diversos pronunciamiento del Tribunal Supremo favorables a la concesión de la prestación de maternidad a los padres comitentes en un contrato de gestación subrogada, encontrándonos, por tanto, ante un pseudoreglamento interno sin Ley previa ${ }^{24}$. No obstante, pese a que jurídicamente dichas consultas no tienen efecto alguno por no ser fuentes de derecho, creemos importante su análisis dado que éstas tendrán una importancia práctica elemental a la hora de determinar cual es la postura de la entidad gestora relativa a las prestaciones de maternidad y paternidad en los supuestos de gestación subrogada.

27. Como requisito previo esencial al reconocimiento del derecho a la prestación por maternidad, el INSS estableció la necesidad de que previamente se hubiera practicado la inscripción de la filiación del recién nacido en el Registro Civil español ${ }^{25}$, quedando así determinada la misma a favor de los padres comitentes ${ }^{26}$. Sin embargo, este reconocimiento se realizaba de una forma parcial o peculiar. Por ello, a continuación, destacaremos algunas de estas peculiaridades:

\footnotetext{
${ }^{20}$ STSJ País Vasco de 17 de abril de 2018, n 1320/2018, ECLI:ES:TSJPV:2018:1320.

${ }^{21}$ STS de 25 de octubre de 2016, n 5375/2016, ECLI:ES:TS:2016:5375; y STS de 30 de noviembre de 2016, n $^{\circ}$ 5801/2016, ECLI:ES:TS:2016:5801.

${ }^{22}$ STS de 25 de octubre de 2016, no 5375/2016, ECLI:ES:TS:2016:5375.

${ }^{23}$ STS de 25 de octubre de 2016, n 5375/2016, ECLI:ES:TS:2016:5375 y STS de 16 de noviembre de 2016, n $5283 / 2016$, ECLI:ES:TS:2016:5283.

${ }^{24}$ J. R. Mecader Uguina, "La creación por el Tribunal Supremo de la prestación por maternidad subrogada: A propósito de la SSTS de 25 de octubre de 2016 y de 16 de noviembre de 2016". Cuadernos de Derecho Transnacional, vol. 9, n ${ }^{\circ} 1$, p. 466.

${ }^{25}$ Ello se regula en la Instrucción de 5 de octubre de 2010 de la DGRN, así como en la Circular de fecha 11 de julio de 2014, que reconoce la plena vigencia de la mencionada Instrucción.

${ }^{26}$ Artículo 113 del Código Civil: La filiación se acredita por la inscripción en el Registro Civil, por el documento o sentencia que la determina legalmente, por la presunción de paternidad matrimonial y, a falta de los medios anteriores, por la posesión de estado. Para la admisión de pruebas distintas a la inscripción se estará a lo dispuesto en la Ley de Registro Civil.
} 
28. El INSS, en relación a la situación protegida, a efectos de la antigua prestación de maternidad del artículo 177 LGSS se consideraba digno de protección el nacimiento de un hijo nacido por el método de gestación subrogada. Y ello debido a que la finalidad de la prestación de maternidad en lo supuestos de adopción y acogimiento y, por extensión, la maternidad subrogada, es la protección y el cuidado del menor, así como el estrechamiento de los lazos de los padres con éste ${ }^{27}$.

29. Por otro lado, el INSS reconoció que el beneficiario de la prestación sería el progenitor, independientemente de su sexo, que hubiera disfrutado del descanso o permiso y reuniere los requisitos establecidos en la normativa social. Y, en los supuestos de disfrute compartido de forma sucesiva o simultanea, ambos progenitores, además de cumplir los requisitos mencionados, debían encontrarse activos laboralmente ${ }^{28}$.

30. En lo que respecta a la fecha del hecho causante, el INSS, asumiendo la doctrina sentada por el Tribunal Superior de Justicia de Castilla-La Mancha en su sentencia 1500/2015, de 27 de mayo, indicó que en los supuestos de gestación subrogada se entendía que la fecha del hecho causante de la prestación es el día del nacimiento del menor. Por lo que los padres comitentes no podrían adelantar el descanso y prestación por maternidad, incluso si los padres tuvieran que desplazarse al país de origen del recién nacido ${ }^{29}$, ni tampoco el disfrute anticipado por voluntad de la madre que se establece en los supuestos de parto biológico. Además, y en relación a los efectos económicos, el subsidio por maternidad tendría efectos desde el día de inicio del período de descanso o período correspondiente, coincidiendo con la fecha del nacimiento del hijo nacido por gestación por sustitución.

31. Al margen de lo anterior, y en relación a la consulta 4/2017, de 20 de febrero, en los supuestos de gestación subrogada parcial ${ }^{30} \mathrm{o}$ donde tan sólo existe un padre comitente y, por tanto, tan sólo éste puede disfrutar del permiso y de la prestación por maternidad, no tendría derecho a solicitar el disfrute del permiso/prestación por paternidad ${ }^{31}$, en aplicación analógica del artículo 23.3 del RD 295/2009, de 6 de marzo. Del mismo modo, a través de la citada consulta, en los supuestos donde la filiación de los hijos nacidos mediante gestación subrogada se determinase a favor de los dos progenitores, las prestaciones de paternidad y maternidad podrían ser compatibles, siempre y cuando los beneficiarios cumplieran los requisitos establecidos al efecto. De tal forma que la prestación por paternidad podía ser disfrutada desde la finalización del permiso por nacimiento del hijo o una vez finalizado el descanso por maternidad del cual es beneficiario el otro progenitor.

32. Por último, la entidad gestora resolvió que aquellos supuestos en los que inicialmente tan sólo constaba la filiación a favor de un progenitor comitente, y, posteriormente, adoptaba al menor la otra persona con la que mantiene una relación conyugal o relación análoga. Así pues, indicó que en estos casos, tan sólo se reconocería una prestación de maternidad, es decir, no sería posible reconocer dos prestaciones de maternidad independientes: una en referencia al nacimiento y otra a la adopción. Por ende, tan solo tendría derecho a la prestación de maternidad el progenitor por el que se determinó en primer lugar la filiación. Pese a ello, nada impedía a que la pareja que reconoció por complacencia al hijo no biológico solicitara disfrutar de la prestación por paternidad.

${ }^{27} \mathrm{M}^{\mathrm{a}}$. D. ORTIZ VIDAL, "La gestación por sustitución y las prestaciones sociales por maternidad/paternidad en España y la novísima jurisprudencia del Tribunal de Justicia de la Unión Europea”, Revista Española de Derecho del Trabajo, 2015 , p. 11.

${ }^{28}$ Artículo 48.4 del Estatuto de los Trabajadores, en relación con el artículo 10.4 del Real Decreto 295/2009, de 6 de marzo.

${ }^{29}$ C. Aragón Gómez, "La legalización de facto de la maternidad subrogada. A propósito de los recientes pronunciamientos de la sala de lo social del tribunal supremo con respecto a las prestaciones por maternidad". Revista de Información Laboral núm. 4/2017. Editorial Aranzadi, S.A.U., Cizur Menor, 2017, p. 16.

${ }^{30}$ Se entiende por gestación subrogada parcial como aquella modalidad de gestación subrogada por medio de la cual la madre portadora, además de prestar su vientre, presta también su material genético, siendo, por tanto madre biológica de la criatura. Este tipo de gestación se efectúa a través de la inseminación artificial utilizando esperma de uno de los contratantes.

${ }^{31}$ A la misma conclusión llegó recientemente el Tribunal Superior de Cataluña. STSJ Catalunya de 25 de enero de 2019, no 664/2019, ECLI:ES:TSJCAT:2019:664. 
33. En consecuencia, antes de la reforma, y como he destacado anteriormente, en los supuestos de gestación subrogada-siempre que se cumplieren los requisitos exigidos-, cualquiera de los dos progenitores comitentes podía acceder a la prestación de maternidad o de paternidad, indistintamente del sexo del progenitor. Es decir, poniendo como ejemplo una pareja heterosexual, perfectamente el progenitor masculino podría disfrutar de la prestación de maternidad y la progenitora de la prestación de paternidad. Y, en el supuesto en el que ambos progenitores hubieran estado activos laboralmente, ambos tenían la opción de compartir la prestación de maternidad y paternidad sucesiva o simultáneamente, sin importar quién iniciaba una prestación u otra.

34. En fin, como hemos venido narrando en el presente estudio, esta interpretación normativa se vino realizando antes de la entrada en vigor del Real Decreto-Ley de 6/2019. Si bien, en la actualidad, tal interpretación ha quedado obsoleta a partir del día 1 de abril de 2019.

\section{La gestación subrogada frente a la prestación por nacimiento y cuidado de menor. Nueva pers- pectivas interpretativas de la norma}

35. Tras la publicación el pasado 7 de marzo del Real Decreto-Ley 6/2019, de 1 de marzo, de medidas urgentes para la garantía de la igualdad de trato y de oportunidades entre mujeres y hombres en el empleo y la ocupación, y con la entrada en vigor el día 1 de abril de las nueva regulación de las prestaciones de maternidad y paternidad a través de la nueva prestación "por nacimiento y cuidado de menor", el sistema de Seguridad Social, en relación a estas prestaciones, ha dado un giro radical de 180 grados.

36. Así, con la entrada en vigor de la mencionada norma, no sólo se ha conglomerado en una única prestación la antigua prestación de maternidad y paternidad en la reciente prestación por nacimiento y cuidado de menor, sino que, además, se han ampliado los tiempos de disfrute al progenitor distinto a la madre biológica, así como los requisitos en el acceso a la prestación.

37. De la lectura de la regulación de la nueva prestación por nacimiento y cuidado de menor podríamos llegar a la conclusión que la gestación subrogada se encuentra dentro de las situaciones protegidas por la norma, pues, en principio se entiendo que todo nacimiento se encuentra amparado en la prestación por nacimiento y cuidado de menor.

38. Dicho esto, como comenté anteriormente, antes de la reforma efectuada por el Real DecretoLey 6/2019, los padres comitentes, una vez acreditada la filiación, podían acceder a la prestación de maternidad y paternidad, teniendo en cuenta que tales prestaciones devenían en incompatibles si éstas se pretendían disfrutar por un único sujeto. Sin embargo, tras la reforma, en el supuesto en el que fuere una pareja la que ha tenido un hijo a través de un contrato de gestación subrogada y aunque la filiación del menor hubiera quedado acreditada a favor de ambos, tan sólo uno de ellos podrá disfrutar de la prestación y permiso por nacimiento y cuidado de menor.

39. Tal conclusión deriva en aplicación expresa del artículo 48.4 del Estatuto de los Trabajadores, pues en los dos primeros párrafos del meritado precepto, se incide expresamente que existirán dos sujetos con derecho al permiso. Por una parte, la madre biológica y, por otro, el progenitor distinto a la madre biológica. A partir de aquí se nos plantea la siguiente cuestión: ¿Qué debemos entender por "madre biológica"?. En mi opinión, tal precepto podría ser entendido de dos formas. Por una parte, y en sentido estricto, como aquella madre que lo ha sido a través de parto biológico; y, por otra, en sentido amplio, como aquella madre que tiene vínculo genético con el menor, independientemente del método o técnica utilizada. Atendiendo al perfil ideológico y a la postura política en relación a la gestación subrogada de la fuerza política que en la actualidad se encuentra en el Gobierno y que aprobó el mencionado Real Decreto-Ley ${ }^{32}$, considero que debiéramos tomar una interpretación restrictiva del término.

\footnotetext{
${ }^{32}$ Para conocer la opinión del Partido Socialista Obrero Español sobre la técnica de la gestación subrogada, debemos remi-
} 
En todo caso, debemos quedar a expensas de que los tribunales den luz al conflicto interpretativo que aquí se plasma.

40. En consonancia con lo anterior, en un supuesto gestación subrogada donde hubiera quedado determinada la filiación a favor de los dos padres comitentes, a través de una interpretación restrictiva del término "madre biológica", tan sólo un miembro o progenitor podrá disfrutar de tal prestación y permiso. En tal supuesto, como decimos, y dado que estaríamos en un supuesto de disfrute de permiso y prestación por el "otro progenitor", éste tendría derecho a un periodo de descanso más reducido en aplicación de la disposición transitoria decimotercera del Estatuto de los Trabajadores ${ }^{33}$ hasta el año 2021, cuando se equipara el periodo de descanso y de prestación para la madre biológica y "para el otro progenitor".

41. En distinta situación nos encontraríamos en aquel que solo es un sujeto el que recurre a la gestación por sustitución y, antes de que el menor cumpliere seis años, la pareja del progenitor comitente, decidiera adoptar al menor. En tal caso, el progenitor biológico podría solicitar la prestación de nacimiento y cuidado de menor asumiendo el rol del "otro progenitor" y la pareja de éste podría solicitar la misma prestación derivada de la adopción del menor.

42. Todas estas conclusiones que anteriormente se manifiestan por nuestra parte, en la actualidad, y dado a la tan reciente reforma realizada por el Ejecutivo y, posteriormente ratificada por la Diputación Permanente, aún no cuenta con respaldo jurisprudencial ni doctrinal. Es por ello que, a día de hoy, no existe solución al conflicto, quedando la futura solución al albur de una futura, necesaria y previsible interpretación jurisprudencial.

\section{Conclusión}

43. Indudablemente el contrato de gestación subrogada es nulo de pleno derecho, pues así se encuentra expresado por voluntad del legislador en el artículo 10, apartado primero, de la Ley de Reproducción Humana Asistida. Del mismo modo, y como he indiciado en la introducción de este artículo, el contrato se podría considerar nulo -según algunos sectores doctrinales- al tener como objeto una parte del organismo de una fémina, encontrándose fuera del comercio de los hombres. No obstante, esta nulidad del contrato de gestación subrogada establecida expresamente en la norma es claramente insuficiente, en tanto en cuanto tan sólo dan solución al génesis del problema, es decir, a la suscripción del contrato de gestación subrogada, pero nada dice acerca de los efectos emanados del mismo los cuales entrañan importantes materias en el ámbito civil y social.

44. Bien, como he comentado con anterioridad, la realidad del fenómeno de la gestación subrogada y el consecuente nacimiento de una nueva realidad plasmada en el nacimiento de un bebé y su integración dentro del ámbito de la familia, ha conllevado que diferentes organismos administrativos intenten dar solución a este defecto o laguna legal a través de una interpretación favorable a los intereses del menor. Así, por ejemplo, la Dirección General de los Registro y del Notariado, a través de la Circular de fecha 11 de julio de 2014, decidió mantener la plena vigencia de la Instrucción de 5 de octubre de

tirnos al programa electoral para las elecciones generales de mayo de 2019. Concretamente, se hace referencia a la gestación subrogada en el punto 6.19 (pág. 245) del programa electoral, donde literalmente se expone que "El Partido Socialista rechaza la gestación por sustitución o gestación subrogada, eufemismo de vientres de alquiler, porque socava los derechos de las mujeres, en especial de las más vulnerables, mercantilizando sus cuerpos y sus funciones reproductivas".

${ }^{33}$ Tal disposición transitoria estipula que, a partir del 1 de abril de 2019, en caso de nacimiento, el otro progenitor contará con un periodo de suspensión total de un periodo de 8 semanas, de las cuales las 2 primeras deberán ser disfrutadas a tiempo completo de forma obligatoria e ininterrumpidamente; en 2020 el otro progenitor contará con un periodo de descanso de 12 semanas, de las cuales las 4 primeras deberán ser disfrutadas a tiempo completo de forma obligatoria e ininterrumpidamente; $y$, finalmente, en 2021 el otro progenitor contará con un periodo de descanso de 16 semanas, de las cuales las 6 primeras deberán ser disfrutadas a tiempo completo de forma obligatoria e ininterrumpidamente. 
2010, arguyendo que, tal y como había señalado el Tribunal Europeo de Derecho Humanos, negar la filiación a favor de los padres comitentes conllevaría un desequilibro sin justificación contra la identidad y privacidad de los menores ${ }^{34}$. Del mismo modo, y asumiendo la doctrina jurisprudencial derivada de las diferentes sentencias dictadas en unificación de doctrina por la Sala Cuarta del Tribunal Supremo, el Instituto Nacional de la Seguridad Social dictó las consultas 29/2016, de 29 de diciembre, y 4/2017, de 20 de febrero, regulando de una forma pseudorreglamentaria ${ }^{35}$ las peculiaridades en el disfrute de la prestación de maternidad y paternidad en los supuestos de gestación subrogada. En consecuencia, han sido nuestros tribunales y, posteriormente, los órganos administrativos, los que han tenido que enfrentarse a esta nueva realidad no regulada por el ordenamiento jurídico, tomando como respaldo una interpretación analógica y extensiva de la norma a fin de dar protección o seguridad jurídica a los menores nacidos mediante este método cuestionable de reproducción asistida.

45. Además, creo relevante reseñar que, pese a la clara nulidad del contrato de gestación subrogada, el legislador español debe dar solución, a través de los instrumentos legislativos correspondientes, a la realidad surgida del contrato mencionado. Y todo ello considerando que dicha regulación no es una opción, sino una obligación establecida en el artículo 39, apartado segundo, de la Constitución Española, en relación con el artículo 14 del mismo texto legal. Tal precepto señala de una forma meridianamente clara la obligación de los poderes públicos de asegurar la protección integral de los hijos nacidos independientemente de su filiación. Pero, en todo caso, esta obligación del legislador no solo proviene de la Constitución Española, sino que también deriva de los tratados y convenciones internacionales suscritos por el Estado español, así como por la normativa europea. De forma ejemplificativa, y en lo que respecta al Derecho internacional, el artículo 5 de la Convención sobre los Derechos del Niño establece que los Estados miembros deberán respetar las responsabilidad, derechos y los deberes de los padres a fin de de que el niño pueda ejercer los derechos reconocidos en la Convención. De otro lado, y en cuanto al Derecho de la Unión Europea, el artículo 24, apartado primero, de la Carta de Derechos Fundamentales de la Unión establece que los menores tienen derecho a la protección y a los cuidados necesarios para su bienestar, siguiendo el aparado segundo del citado artículo afirmando que en todos los actos relativos a los menores llevados a cabo por autoridades públicas o instituciones privadas, el interés superior del menor constituirá una consideración primordial. Por tanto, el Estado tiene la obligación de velar por el interés superior del menor, el cual se plasma, en lo que respecta al Derecho del Trabajo y de la Seguridad Social, a través de las prestaciones y permisos cuya finalidad es el cuidado y atención del menor, como sucede con la prestación y permiso por nacimiento y cuidado de menor ${ }^{36}$, así como de diferentes permisos que permiten conciliar la vida laboral y familiar.

46. Concluyendo, creo necesario que el legislador español ha de dar una solución pacífica y clara a la no regulación de los efectos de la gestación subrogada. Pues, de contrario, como he tratado de señalar, estos menores seguirán encontrándose en una absoluta laguna jurídica, quedando al albur de una mera interpretación jurisprudencial de la normativa social.

\footnotetext{
${ }^{34}$ Estos derechos están recogidos en el artículo 8 de la Convención sobre los derechos del niño adoptada por la Asamblea General de las Naciones Unidas de 20 de noviembre de 1989, así como por el artículo 8 del Convenio Europeo para la protección de los Derechos Humanos y las Libertades Fundamentales.

${ }^{35}$ J. R. Mecader UGuina, op. cit, p. 466.

${ }^{36} \mathrm{M}^{\mathrm{a}}$. D. ORTIZ VidAL, op cit, p. 11.
} 